OPEN ACCESS

Edited by:

Avelino Alvarez-Ordóñez,

Teagasc Food Research Centre,

Ireland

Reviewed by:

Efstathios D. Giaouris,

University of the Aegean, Greece

Claus Sternberg,

Technical University of Denmark,

Denmark

*Correspondence:

Belen Orgaz

belen@vet.ucm.es

Specialty section

This article was submitted to

Food Microbiology,

a section of the journal

Frontiers in Microbiology

Received: 02 October 2015

Accepted: 25 January 2016

Published: 15 February 2016

Citation:

Puga CH, Orgaz B and SanJose $C$

(2016) Listeria monocytogenes

Impact on Mature or Old

Pseudomonas fluorescens Biofilms

During Growth at 4 and $20^{\circ} \mathrm{C}$.

Front. Microbiol. 7:134.

doi: 10.3389/fmicb.2016.00134

\section{Listeria monocytogenes Impact on Mature or Old Pseudomonas fluorescens Biofilms During Growth at 4 and $20^{\circ} \mathrm{C}$}

\section{Carmen H. Puga, Belen Orgaz* and Carmen SanJose}

Department of Nutrition, Food Science and Technology, Faculty of Veterinary, Complutense University of Madrid, Madrid, Spain

Changes in spatial organization, as observed by confocal laser scanning microscopy (CLSM), viable cell content, biovolume, and substratum surface coverage of the biofilms formed on glass by Pseudomonas fluorescens resulting from co-culture with Listeria monocytogenes, were examined. Two strains of L. monocytogenes, two culture temperatures and two biofilm developmental stages were investigated. Both L. monocytogenes strains, a persistently sampled isolate (collected repeatedly along 3 years from a meat factory) and Scott $A$, induced shrinkage in matrix volume, both at $20^{\circ} \mathrm{C}$ and $4^{\circ} \mathrm{C}$, in mature or old biofilms, without loss of $P$. fluorescens cell count per surface unit. The nearly homogeneous pattern of surface coverage shown by mono-species $P$. fluorescens biofilms, turned into more irregular layouts in co-culture with $L$. monocytogenes. The upper layer of both mono and dual-species biofilms turned to predominantly consist of matrix, with plenty of viable cells underneath, in old biofilms cultured at $20^{\circ} \mathrm{C}$, but not in those grown at $4^{\circ} \mathrm{C}$. Between 15 and $56 \%$ of the substratum area was covered by biofilm, the extent depending on temperature, time and L. monocytogenes strain. Real biofilms in food-related surfaces may thus be very heterogeneous regarding their superficial components, i.e., those more accessible to disinfectants. It is therefore a hygienic challenge to choose an adequate agent to disrupt them.

Keywords: Listeria monocytogenes, Pseudomonas fluorescens, biofilms, interspecies interactions, low temperature, CLSM

\section{INTRODUCTION}

Known previously as an animal pathogen and ubiquitous in nature, Listeria monocytogenes emerged as a foodborne human pathogen in the 1980s (Ryser and Marth, 2007; Warriner and Namvar, 2009). That can be attributed to an unprecedented global improvement of hygienic practices in food industry from the 1970s, including both better cleaning and disinfection methods and a more widespread use of refrigeration. This public health progress, reducing the prevalence of most foodborne diseases, had an undesirable side effect. Elimination by lowtemperature of the constraint of microbial competitors implied a new chance for Listeria, one of the few psychrotrophic bacterial pathogens, to thrive in refrigerated foods. As adequate storage of pasteurized and/or Ready To Eat (RTE) foods requires low temperatures, cold-tolerant, 
i.e., psychrotrophic, bacteria tend to be selected in those foods. That is the case of Pseudomonas (fluorescens, putida, fragi), able to cause important quality defects in protein-rich foods (Andreani et al., 2015).

Coinciding with this trend and the development of microbial ecology approaches to food safety and quality, there has been an increasing interest in biofilms (Costerton et al., 1995; Srey et al., 2013). Pseudomonas species were soon characterized as quick and thick biofilm producers, even the non-pathogenic species, often dominant in food spoilage. Their understanding has been driven by the far more abundant clinical and basic information on Pseudomonas aeruginosa's biofilms (Silby et al., 2011; Mann and Wozniak, 2012). Many authors also have studied L. monocytogenes's carrying biofilms (Moretro and Langsrud, 2004; Rieu et al., 2008; Bonsaglia et al., 2014; Guilbaud et al., 2015).

Interactions between Pseudomonas and L. monocytogenes in biofilms were initially described by Sasahara and Zottola (1993). Their claim on the need of a primary surface colonizer, such as Pseudomonas (in that case $P$. fragi) for $L$. monocytogenes attachment, was a very relevant one in its time and not just for the food microbiology field. Multispecies biofilms have attracted attention mostly because their partners can resist harder antimicrobial challenges than single species biofilms (Burmølle et al., 2006; Simões et al., 2009; Sanchez-Vizuete et al., 2015) and because they are now acknowledged to be widely distributed in both natural and industrial environments. Various hypotheses have been used to investigate the specific properties of mixed biofilms and to characterize the interactions between the partners and toward newcomers (Carpentier and Chassaing, 2004; Moons et al., 2009; Yang et al., 2011; Elias and Banin, 2012; Burmølle et al., 2014; Giaouris et al., 2014, 2015; Jahid and Ha, 2014; Bridier et al., 2015) and many attempts have been made to identify the natural biofilm cohabitants at critical sites, including specific food related facilities (Fox et al., 2014; Røder et al., 2015; Rodríguez-López et al., 2015).

New insights on the regulation of biofilm formation are helping to deepen the knowledge about the sort of biofilms that can be found in food industry, where multiple strategies to prevent or delay microbial growth are commonly combined to preserve foods (low temperature, low $\mathrm{pH}$, high osmotic pressure, modified atmospheres, presence of natural antimicrobials, etc.). Food preservation conditions are adverse situations that may activate stress response in some of the present microorganisms, which are thus selected. Certain Pseudomonas and L. monocytogenes strains belong to those selected at low temperatures (Moretro and Langsrud, 2004; Hemery et al., 2007; Chan and Wiedmann, 2009; Ortiz et al., 2010; Silby et al., 2011; Mann and Wozniak, 2012; Valderrama and Cutter, 2013; Rodríguez-López et al., 2015) and they may jointly form biofilm on raw materials, foods, and inert surfaces at food handling facilities. Though refrigeration tends to be used in food processing and food service facilities during operating hours, higher environmental temperatures tend to occur during pauses or implementation of cleaning and disinfection tasks. Biofilm life may thus switch from 4 to $20^{\circ} \mathrm{C}$, or even larger intervals at those sites. L. monocytogenes strains that have been found to persist for months or even years (Ortiz et al., 2010; Carpentier and Cerf, 2011) are likely to have often experienced changing culture conditions, apart from partial elimination and repeated sanitizer exposure, by daily but not fully effective cleaning and disinfection cycles. Development of more effective, cheap, and sustainable eradication methods requires more information on the target biofilms where L. monocytogenes inhabits.

This study, still in the track of Sasahara and Zottola (1993), tries to follow the formation and aging of $P$. fluorescens and L. monocytogenes mixed biofilms in temperature conditions that are realistic for food industry. One $P$. fluorescens and one L. monocytogenes strain of food industry origin were used, adding well known L. monocytogenes Scott A for comparison. Viability counting was combined with culture-independent evaluations, to get a hint of the heterogeneity in biofilm setups that could be useful for food hygiene purposes. Previous evidence of spatial distribution in these dual-species biofilms has already been reported by the same authors (Puga et al., 2014).

\section{MATERIALS AND METHODS}

\section{Bacterial Strains}

Pseudomonas fluorescens ATCC $948^{\mathrm{TM}}$ and two strains of L. monocytogenes were selected as biofilm former organisms. S1 is a L. monocytogenes persistent strain, (serotype 1/2a; lineage II) isolated by Ortiz et al. (2010) from an Iberian pig slaughterhouse and its associated processing plant; the other L. monocytogenes was the reference clinical strain Scott A (4b; lineage I). All of them were stored at $-20^{\circ} \mathrm{C}$ in Tryptone Soya Broth (TSB, OXOID) with $15 \%$ glycerol. Preinocula were obtained in TSB after $24 \mathrm{~h}$ incubation at $20^{\circ} \mathrm{C}$ while shaking $(80 \mathrm{rpm})$ to reach mid exponential phase. Working cultures were obtained from this as follows: $100 \mu \mathrm{L}$ of preinocula were transferred into a test tube containing fresh TSB and incubated at $20^{\circ} \mathrm{C}$ for $24 \mathrm{~h}$. Then, cells were harvested by centrifugation at $4000 \times g$ for $10 \mathrm{~min}$, washed twice in sterile TSB and their $\mathrm{OD}_{600}$ adjusted (0.12), to be used as inocula, in order to reach $10^{4} \mathrm{CFU} \cdot \mathrm{mL}^{-1}$ for each bacterial strain at the start of either single or binary cultures.

\section{Experimental System}

Biofilms developed on single-use $22 \mathrm{~mm} \times 22 \mathrm{~mm}$ thin, borosilicate commercial microscope glass coverslips. These coverslips provide single-use, relatively wide, clean and undamaged smooth surfaces, without scratches or other microtopographic irregularities, moderately more hydrophilic than stainless steel, and allowing for more reproducible biofilms than reusable metal coupons. As described in Orgaz et al. (2011), 16 coverslips were held vertically by marginal insertion into the narrow radial slits of a Teflon carousel platform $(6.6 \mathrm{~cm}$ diameter). The platform and its lid were assembled by an axial metallic rod for handling and placed into a $600 \mathrm{~mL}$ beaker (Figure 1) which was heat-sterilized as a unit, before aseptically introducing $60 \mathrm{~mL}$ of inoculated TSB. The glass coupons used in this study as substratum surfaces, were immersed in the liquid culture medium, which covered two thirds of the coupon area. 


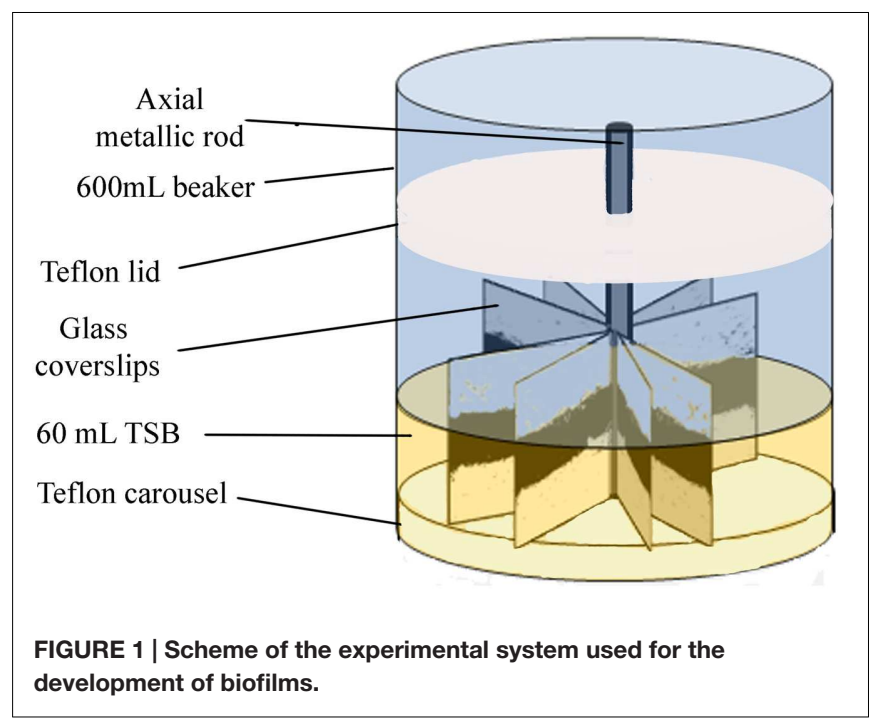

To check whether the covered area was homogeneous in terms of biofilm colonization, the coupon was arbitrarily divided into three equal horizontal bands. The top one, not covered by liquid was the Air-Phase (AP). The intermediate one (ALI), covered and located around the Air-Liquid Interphase, was intensely aerated and exposed to liquid shear during rotation shaking. The Fully Immersed one (FI), less aerated zone, was at the bottom. For multispecies biofilms containing P. fluorescens and one of the two L. monocytogenes strains afore mentioned, both bacteria were inoculated at the same level (1:1). P. fluorescens mono-species biofilms were used as controls. Incubation was carried out at $20^{\circ} \mathrm{C}$ or $4^{\circ} \mathrm{C}$, in a rotating shaker at $80 \mathrm{rpm}$. Under these conditions, biofilm growth occupied almost $70 \%$ of the coverslip's surface. Samples corresponding to "mature biofilm" were taken after $48 \mathrm{~h}$ at $20^{\circ} \mathrm{C}$, or 10 days at $4^{\circ} \mathrm{C}$. Those taken at $20^{\circ} \mathrm{C} / 144 \mathrm{~h}$ or $4^{\circ} \mathrm{C} / 20$ days were here called "old biofilm."

\section{Cell Recovery and Counting}

For sampling biofilm cells, glass coverslips were withdrawn with tweezers, and were carefully rinsed in sterile $0.9 \% \mathrm{NaCl}$ to discard weakly attached cells. Then, attached cells of both coverslip faces were removed by swabbing (withdrawing all attached material from both coverslip faces with a cotton swab that was later immersed into an sterile tube containing $1.5 \mathrm{~mL}$ peptone water). Tubes were then vigorously stirred in a vortex to break up cell aggregates. Biofilm cells were decimally diluted in peptone water to be plated according to the drop method described by Hoben and Somasegaran (1982). Briefly, three $20 \mu \mathrm{L}$ drops of each dilution were deposited onto plates of selective media, PALCAM (OXOID) or Pseudomonas Agar Base (PAB, OXOID), for counting Listeria sp. and Pseudomonas sp., respectively, in mono and dual-species biofilms. For purity control, plating on Tryptone Soy Agar (TSA, OXOID) was used to visually detect potential contaminant colonies. Counting was performed after $48 \mathrm{~h}$ incubation, at $37^{\circ} \mathrm{C}$ or $30^{\circ} \mathrm{C}$, for L. monocytogenes or P. fluorescens, respectively. The results presented are the average of two coupons per experiment and three independent experiments $(n=6)$.

\section{Confocal Laser Scanning Microscopy (CLSM)}

The structural effects of $L$. monocytogenes on dual-species biofilms structure were examined by CLSM. For observation, the biofilms developed on the glass coverslips were rinsed with sterile $0.9 \% \mathrm{NaCl}$ and stained with Syto 13 (S7575, Life Technologies) which labels all bacteria in a population, and CalcoFluor White (18909, FLUKA) a non-specific fluorochrome that binds to cellulose and other polysaccharides present in the extracellular polymeric substances (EPS) biofilm matrix. Thus, for quantification, green here corresponds to cells, whereas blue corresponds to EPS. Five representative regions of $0.12 \mathrm{~mm} \times 0.12 \mathrm{~mm}$ located at the air-liquid-interphase zone were selected from each coupon. For this, the side of the coupon $(22 \mathrm{~mm})$ was divided into five regions (4.4 mm each one) and the center point of each one was later scanned. CLSM images of these locations were obtained with a FLUOVIEW ${ }^{\circledR}$ FV 1200 Laser Scanning Confocal Microscope (OLYMPUS) and an oil immersion objective lens 60X. Three-dimensional projections (Maximun Intensity Projection, MIP) were reconstructed from z-stacks using IMARIS ${ }^{\oplus} 8.1$ software (BITPLANE AG, Zurich, Switzerland). The parameter here called biovolume was calculated using the MeasurementPro module of IMARIS; the whole image was thus segmented into two channels, green and blue, to estimate the volume occupied by either cells or EPS. The total biovolume $\left(\mu \mathrm{m}^{3}\right)$ was the sum of cells and EPS biovolumes, using the five fields. Biovolume reduction measurements were here calculated considering the biovolume occupied by P. fluorescens in mono-species biofilms represented 100\%. The Matrix/Cell ratio was calculated for every image.

\section{Biomass Determination}

To evaluate the surface coverage of the attached biomass (cells plus EPS matrix) five coverslips of each type of biofilms (i.e., young and old biofilms; warm and cold biofilms; P. fluorescens mono-species and dual species with $L$. monocytogenes) were dried and stained for $2 \mathrm{~min}$ in a $1 \%$ Coomassie Blue (Brilliant Blue $\mathrm{R}$, SIGMA) solution in acetic acid/methanol/water (1:2.5:6.5) mixture. This step was repeated twice. Once rinsed and dried again, the coverslips were scanned using a $600 \mathrm{dpi}$ resolution (HP Scanjet 300) and analyzed using ImageJ (http://imagej.net). Densitometry allows analyzing the whole area of the stained coupon in comparison with confocal microscopy where fields are much smaller. The aim here was to integrate the biomass results of the whole coupon, segmented in areas with different aeration. A parameter called $\%$ of covered area was estimated for every image. For this, the scanned images were transformed into a binary system (i.e., black and white) and the surface occupied by black was quantified. Each coupon was divided into three zones, as described before. For calculations, the occupation in the air phase was discarded, as that area was scarcely covered, assuming as total biomass coverage the sum of the air-liquid interphase and the fully immersed zone (Figure 2). 


\section{RESULTS}

\section{Effects of $L$. monocytogenes Co-culture on $P$. fluorescens's Biofilm at $20^{\circ} \mathrm{C}$}

What is here called "mature" or fully grown biofilm corresponds to the maximum attached population attained in these batch conditions $\left(48 \mathrm{~h}\right.$ at $20^{\circ} \mathrm{C}$ ), with around $4 \times 10^{7} \mathrm{CFU}$ of $P$. fluorescens $/ \mathrm{cm}^{2}$ (Table 1). At that stage, viable $P$. fluorescens cell numbers experienced almost no change if co-cultured with a L. monocytogenes strain. Both strains of L. monocytogenes grew more slowly than $P$. fluorescens in the binary biofilms at $20^{\circ} \mathrm{C}$, particularly S1 $(7.7 \log$ versus $5.9 \log )$. CLSM images, which in this study did not discriminate $P$. fluorescens and L. monocytogenes cells (Figure 3A), showed a rather homogeneous surface coverage in the case of single species $P$. fluorescens biofilms and a patchy, heterogeneous pattern for the binary biofilms, in spite of the low L. monocytogenes numbers (Table 1). As seen in Table 2, displaying cell and matrix biovolumes, and Table 3, presenting biomass distribution and substrate surface occupation, co-culture resulted in a decrease in biofilm biovolume and maximal thickness,. Considering that $P$. fluorescens viable cell number did not decrease, the outcome was a rise in density, in compactness. The matrix to cell ratio (Table 2) which was 0.7 in the single species $P$. fluorescens biofilms, was not changed by the presence of the food industry-persistent S1 strain of L. monocytogenes, but went down to 0.2 when co-cultured with $L$. monocytogenes Scott A. This strain caused a $75-80 \%$ matrix loss in binary biofilms (Table 2).

Binary old biofilms ( $144 \mathrm{~h}$ at $20^{\circ} \mathrm{C}$ ) were clearly into the dispersal stage, having already lost 1-2 log of its viable P. fluorescens cells (Table 1). By then, L. monocytogenes Scott A counts were $1 \log$ less than those of $P$. fluorescens and the S1 strain, $2 \log$ less, though still representing a substantial population in the binary biofilm $\left(2 \times 10^{4} \mathrm{CFU}\right.$ $\mathrm{cm}^{-2}$; Table 1). Maximal biofilm thickness (Table 2) in both mono and dual-species biofilms had at that stage decreased by approximately $50 \%$ with respect to their corresponding mature biofilms (from 37 to $22 \mu \mathrm{m}$ on average). It is to be noticed a change in accessibility of the biofilm cells, which appeared then covered by matrix (Figure 3B). Remaining

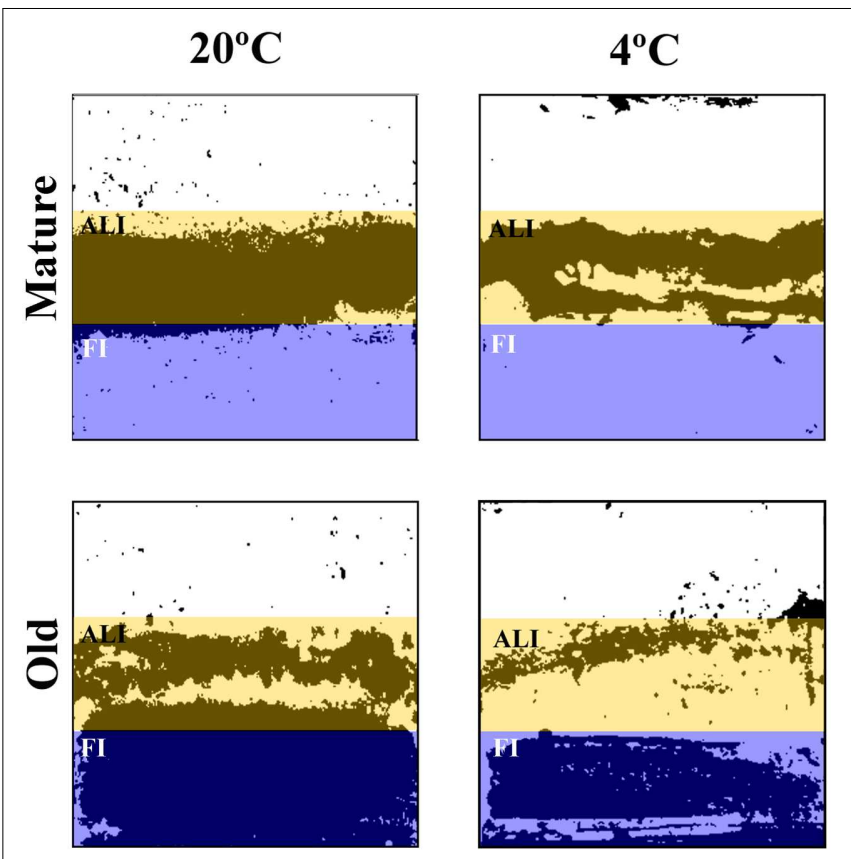

FIGURE 2 | Scanned coupons black and white images of mature and old $\boldsymbol{P}$. fluorescens mono-species biofilms. Colored boxes mark the two different areas analyzed. Mature: $20^{\circ} \mathrm{C} / 48 \mathrm{~h} ; 4^{\circ} \mathrm{C} / 10$ days. Old: $20^{\circ} \mathrm{C} / 144 \mathrm{~h}$; $4^{\circ} \mathrm{C} / 20$ days.

cells were thus underneath, packed in a deeper, more protected position, in both the mono and dual-species old biofilms.

\section{Effects of $L$. monocytogenes Co-culture on $P$. fluorescens's Biofilm at $4^{\circ} \mathrm{C}$}

In a previous work of this group (Puga et al., 2014), it was observed that biofilms growing at $4^{\circ} \mathrm{C}$ for 10 days were approaching the end of the stage featuring a net increase of attached cells per surface unit. Mono-species $P$. fluorescens biofilms matured at low temperature had about 1 log less viable counts $/ \mathrm{cm}^{2}$ than when matured at $20^{\circ} \mathrm{C}$ (Table 1) and presented about half their maximal thickness (Table 2). Just as

TABLE 1 | $P$. fluorescens and $L$. monocytogenes viable cells in biofilms.

\begin{tabular}{|c|c|c|c|c|c|}
\hline \multirow[t]{2}{*}{ Sample* } & \multirow{2}{*}{$\begin{array}{c}\mathrm{P} \\
\left(\log _{10} \mathrm{CFU} \mathrm{cm}\right. \\
\end{array}$} & \multicolumn{2}{|c|}{$\begin{array}{c}\text { PI } \\
\left(\log _{10} \mathrm{CFU} \mathrm{cm}{ }^{-2}\right)\end{array}$} & \multicolumn{2}{|c|}{$\begin{array}{c}\text { PSc } \\
\left(\log _{10} \text { CPU cm}\right. \\
\text { ch })\end{array}$} \\
\hline & & $\begin{array}{c}P \text { fluorescens } \\
\mathrm{X} \pm \mathrm{SD}\end{array}$ & $\begin{array}{l}\text { L. monocytogenes } \\
\qquad \pm \mathrm{SD}\end{array}$ & $\begin{array}{c}P \text { fluorescens } \\
X \pm S D\end{array}$ & $\begin{array}{c}\text { L. monocytogenes } \\
\text { X } \pm \text { SD }\end{array}$ \\
\hline $20^{\circ} \mathrm{C} /$ mature & $7.6 \pm 0.1^{\mathrm{aA}}$ & $7.7 \pm 0.1^{\mathrm{aA}}$ & $5.9 \pm 0.6^{\mathrm{aC}}$ & $7.5 \pm 0.3^{\mathrm{aA}, \mathrm{E}}$ & $6.7 \pm 0.3^{a B, C}$ \\
\hline $20^{\circ} \mathrm{C} / \mathrm{old}$ & $5.7 \pm 0.1^{\mathrm{cB}}$ & $6.2 \pm 0.1^{\mathrm{bA}}$ & $4.4 \pm 0.2^{b c}$ & $6.3 \pm 0.0^{\mathrm{bA}}$ & $5.4 \pm 0.1^{\mathrm{bB}}$ \\
\hline $4^{\circ} \mathrm{C} /$ mature & $6.6 \pm 0.8^{b, c A}$ & $6.7 \pm 0.1^{\mathrm{bA}}$ & $3.1 \pm 0.1^{\mathrm{cC}}$ & $6.4 \pm 0.0^{\mathrm{bA}}$ & $4.4 \pm 0.2^{\mathrm{cB}}$ \\
\hline $4^{\circ} \mathrm{C} / \mathrm{old}$ & $6.2 \pm 0.1^{\mathrm{cA}}$ & $5.8 \pm 0.7^{\mathrm{bA}}$ & $5.6 \pm 0.2^{\mathrm{aA}, \mathrm{B}}$ & $5.0 \pm 0.2^{\mathrm{cB}, \mathrm{C}}$ & $4.6 \pm 0.2^{\mathrm{cC}}$ \\
\hline
\end{tabular}

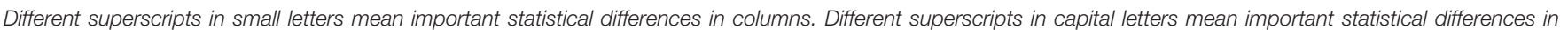

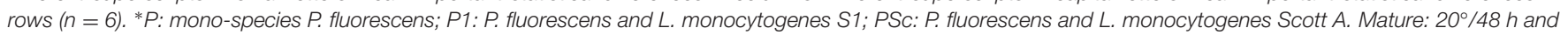
4\% /10 days; Old: $20 \% / 144 \mathrm{~h}$ and $4 \% / 20$ days. 
TABLE 2 | Structural parameters obtained from CLSM images in Figure 3.

\begin{tabular}{|c|c|c|c|c|c|c|}
\hline \multirow[t]{2}{*}{ Sample* } & \multicolumn{3}{|c|}{$20^{\circ} \mathrm{C}$ Biofilms } & \multicolumn{3}{|c|}{$4^{\circ} \mathrm{C}$ Biofilms } \\
\hline & $\begin{array}{l}\text { Max. BF } \\
\text { Thickness }(\mu \mathrm{m})\end{array}$ & $\begin{array}{c}\text { Biovolume } \\
\text { reduction (\%) }\end{array}$ & Matrix/ Cells ratio & $\begin{array}{c}\text { Max. BF } \\
\text { thickness }(\mu \mathrm{m})\end{array}$ & $\begin{array}{c}\text { Biovolume } \\
\text { reduction (\%) }\end{array}$ & Matrix/ Cells ratio \\
\hline P-mature & $43 \pm 7$ & & 0.7 & $23 \pm 10$ & & 0.9 \\
\hline Pl-mature & $31 \pm 5$ & 27 & 0.7 & $29 \pm 7$ & 22 & 0.6 \\
\hline PSc-mature & $39 \pm 9$ & 55 & 0.2 & $13 \pm 5$ & 39 & 0.8 \\
\hline P-old & $20 \pm 1$ & & 1.1 & $27 \pm 13$ & & 0.7 \\
\hline Pl-old & $21 \pm 3$ & 67 & 1.0 & $13 \pm 4$ & 96 & 0.1 \\
\hline PSc-old & $26 \pm 5$ & 73 & 1.0 & $26 \pm 1$ & 55 & 0.9 \\
\hline
\end{tabular}

*P: mono-species P. fluorescens; P1: P. fluorescens and L. monocytogenes S1; PSc: P. fluorescens and L. monocytogenes Scott A. Mature: $20^{\circ} / 48$ h and $4 \% 10$ days; Old: $20^{\circ} / 144 \mathrm{~h}$ and $4 \% / 20$ days.

TABLE 3 | Structural parameters obtained from scanned coupons analyzed by ImageJ of the biofilms in the ALI: Air-Liquid Interphase and FI: Fully Immersed bands of the coupons shown in Figure 2.

\begin{tabular}{|c|c|c|c|c|c|c|}
\hline \multirow[t]{3}{*}{ Sample* } & \multicolumn{3}{|c|}{$20^{\circ} \mathrm{C}$ Biofilms } & \multicolumn{3}{|c|}{$4^{\circ} \mathrm{C}$ Biofilms } \\
\hline & \multicolumn{2}{|c|}{ Biomass distribution } & \multirow[t]{2}{*}{ Covered area $(\%)$} & \multicolumn{2}{|c|}{ Biomass distribution } & \multirow[t]{2}{*}{ Covered area (\%) } \\
\hline & ALI & FT & & ALI & FT & \\
\hline P-mature & $90 \pm 3$ & $10 \pm 4$ & $30 \pm 2^{b}$ & $81-$ & $19-$ & $26 \pm 7^{a}$ \\
\hline Pl-mature & $84 \pm 5$ & $15 \pm 5$ & $44 \pm 5^{a}$ & $84 \pm 9$ & $16 \pm 9$ & $19 \pm /^{\mathrm{a}}$ \\
\hline PSc-mature & $99 \pm 0$ & $1 \pm 0$ & $28 \pm 1^{b}$ & $94 \pm 4$ & $6 \pm 4$ & $16 \pm /^{\mathrm{a}}$ \\
\hline P-old & $35 \pm 4$ & $65 \pm 4$ & $48 \pm 7^{b}$ & $21 \pm 8$ & $80 \pm 8$ & $32 \pm 3^{a}$ \\
\hline Pl-old & $48 \pm 4$ & $52 \pm 4$ & $57 \pm 3^{a}$ & $22 \pm 6$ & $77 \pm 6$ & $36 \pm 4^{a}$ \\
\hline PSc-old & $27 \pm 7$ & $73 \pm 7$ & $37 \pm 4^{c}$ & $17 \pm 4$ & $83 \pm 4$ & $32 \pm 3^{a}$ \\
\hline
\end{tabular}

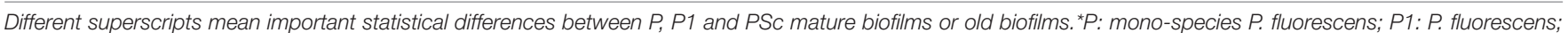
and L. monocytogenes S1; PSc: P. fluorescens and L. monocytogenes Scott A. Mature: 20\%/48 h and 4\%/10 days; Old: $20^{\circ} / 144 \mathrm{~h}$ and $4^{\circ} / 20$ days.

at $20^{\circ} \mathrm{C}$, however, in mature binary biofilms obtained at $4^{\circ} \mathrm{C}$, L. monocytogenes viable counts were 1-2 log inferior to those of $P$. fluorescens, which remained as in the mono-species controls (Table 1). Global biovolume reduction due to co-culture was L. monocytogenes-strain dependent, being more severe in old than in mature biofilms (Table 2). Regarding matrix distribution, whereas in the mono-species biofilms EPS appeared mostly layered on top of the cells, in the binary biofilms there was a considerable amount of matrix material scattered on void substratum spaces, away from cells (Figure 3).

Pseudomonas fluorescens population level in the old biofilms (20 days at $4^{\circ} \mathrm{C}$ ) was just slightly lower than in the mature ones (Table 1). This could be either due to moderate dispersal or to regrowth, compensating in number the dispersed cells. Global biovolume reduction strongly depended on L. monocytogenes strain. It was the food industry-persistent strain S1 that caused more shrinkage in binary biofilms: a $96 \%$ loss in biovolume. It also brought about a $50 \%$ loss in maximal biofilm thickness and a sharp fall, from 0.6 to 0.1 , in matrix to cell ratio (Table 2, Figure 3).

\section{Aeration in Mono or Dual-Species $P$. fluorescens Biofilm Development}

Every experimental system to develop biofilms has its own particularities. The coupons used in this study have areas with different aeration. To find out how could this influence local biofilm formation and affect the significance of temperature, age, and species interaction, the coupon surface was divided into three band zones as described in the "Material and Methods" section and the biomass attached to each of them (Figure 2) was quantified (Table 3). As it is shown in the whole coupon images of Figure 2, at any incubation moment, important zonal differences in biomass coverage did happen. For one thing, the Fully Immersed surface was colonized after the more aerated zone. Indeed, in mature biofilms most of the biomass was located in the more aerated zone (ALI; ranging from 81 to 99\%), whereas in old biofilms the percentage of biomass located in the fully immersed zone (FI) increased (ranging from 52 to $83 \%$; Table 3). The latter effect was much more intense in cold biofilms. No significant biomass shrinkage was observed as a result of species interaction, independently of the temperature of biofilms development (Table 3). Overall surface coverage reached maxima of 57 and $36 \%$ in cultures at 20 and $4^{\circ} \mathrm{C}$, respectively. These surface coverages were achieved for the old dual-species biofilms between P. fluorescens and L. monocytogenes strain S1.

\section{DISCUSSION}

Biofilms formation in the food industry is a serious concern, especially of those where L. monocytogenes can persist. More 

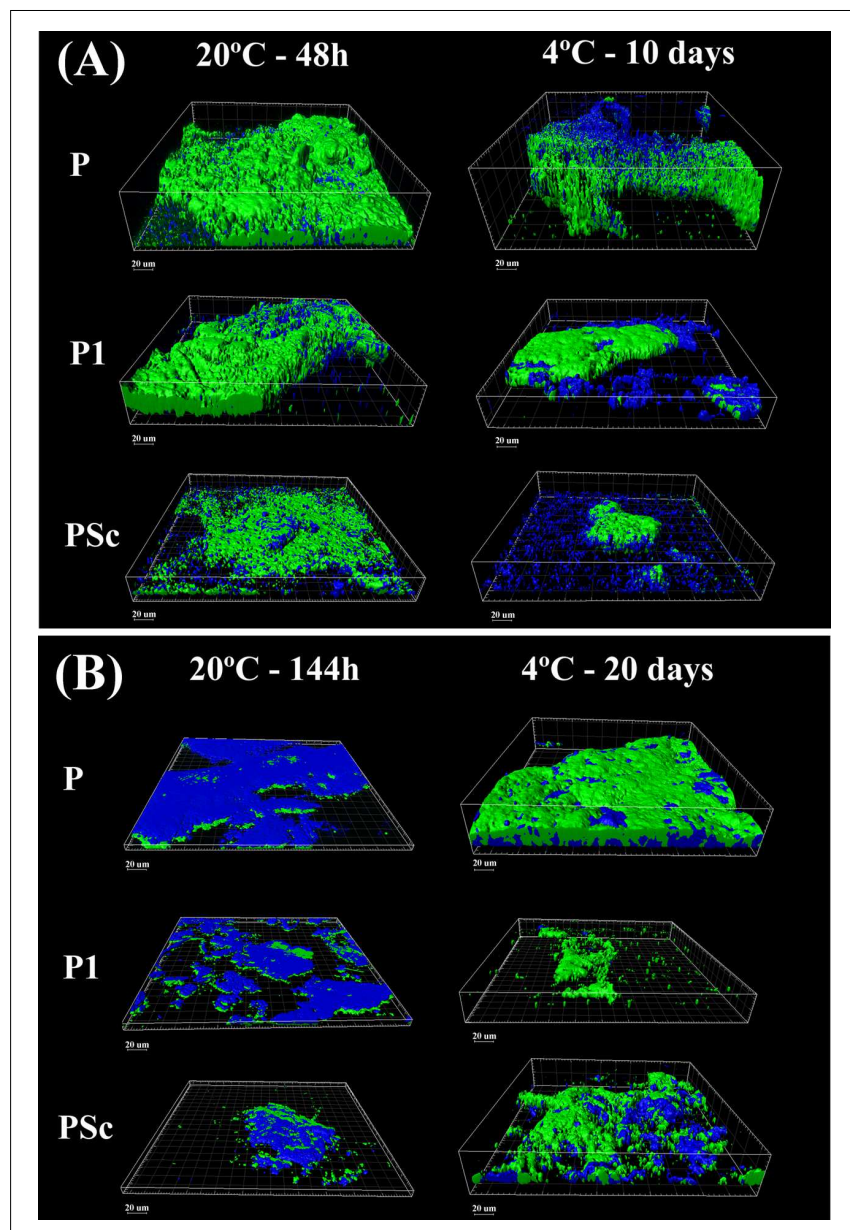

FIGURE 3 | Three-dimensional CLSM reconstruction of mature (A) and old (B) $P$. fluorescens-carrying biofilms obtained at $20^{\circ} \mathrm{C}$ or $4^{\circ} \mathrm{C}$. Green: cells; blue: EPS matrix. P: P. fluorescens biofilms; P1: mixed $P$. fluorescens and $L$. monocytogenes $S 1$ biofilms; PSc: mixed P. fluorescens and L. monocytogenes Scott A biofilms.

information on these biofilms could be helpful to develop strategies to successfully eradicate them. Nevertheless, conditions usually found in food processing plants, such as low temperature, are often disregarded when developing target biofilms. In this work, the impact that low temperature and biofilm aging have on the population and the structure of mixed biofilms has been evaluated. As biofilm forming microorganisms, one P. fluorescens and one L. monocytogenes strain of food industry origin were used, plus the reference strain Scott A for comparison. Viability counting was combined with imaging techniques, to gain an insight in the features of these biofilms that could serve as starting point for improving the current cleaning and disinfection strategies.

When surface biomass was measured in the more or less aerated zones of the coupons, it was confirmed that oxygen availability determined a different pattern of surface colonization at the different coupon areas (Figure 2). Similar situations can be found in food industry; biofilms with heterogeneous age and physiology are to be expected in close proximity in real locations. Physiological heterogeneity is inherent to complex natural communities (Stewart and Franklin, 2008). On the other hand, these coupons with zonal biofilm heterogeneity, are the ones we use as experimental system. That means that viable cell countings, such as those in Table 1, are average measurements, integrating physiologically heterogeneous biofilm situations across a coupon $\left(650 \mathrm{~mm}^{2}\right.$ surface $)$ and where at least six coupons were averaged. By comparison, CLSM fields $\left(0.014 \mathrm{~mm}^{2}\right)$ show detailed but very localized information (five fields are summed up for volumetric measurements). The two techniques (viable cell counting and CLSM) supply different but complementary information.

The outcome of species interaction on surfaces is assumed to depend on culture conditions, particular species or strains involved, sequence of arrival to the surface (Carpentier and Chassaing, 2004) and the respective population sizes (Mellefont et al., 2008). Regarding population levels, in the present study, those of L. monocytogenes were initially as large as those of $P$. fluorescens; this proportion is unrealistic for food industry as a whole, where different species of Pseudomonas are far more prevalent. However, high local concentrations of L. monocytogenes may occur at particular food industry harborage sites, considering its general endurance (Moretro and Langsrud, 2004; Ryser and Marth, 2007; Valderrama and Cutter, 2013) and a good desiccation survival ability (Alavi and Hansen, 2013). Only two L. monocytogenes strains were tested here, but previous studies with different food industry isolates (Puga et al., 2014) support and complement the present results. There, a commensal relationship was found to exist in biofilms between the two species, with a stimulation of L. monocytogenes population without an effect on that of $P$. fluorescens, in terms of viable cell numbers. Besides, a stratified species distribution was seen, using specific species labeling, with L. monocytogenes occupying the deeper, more anaerobic biofilm layers, in spite of its late incorporation into the biofilm. In the present work, coculture with $L$. monocytogenes was observed to induce a reduction in P. fluorescens biofilm volume (Figure 3, Tables 2 and 3) without decrease of its cell counts per surface unit (Table 1). According to early assumptions on the role of species interaction for joint surface colonization, a good biofilm former species, such as Pseudomonas, would play the role of primary colonizer and provide shelter for poor biofilm formers such as L. monocytogenes (Sasahara and Zottola, 1993). In this case, L. monocytogenes seem to actively redesign the biofilms formed by $P$. fluorescens (Puga et al., 2014) favoring its own proliferation in there and introducing extra compactness in their structure.

Listeria monocytogenes counts in this sort of denser biofilms may be underestimated by experimental systems such as those using crystal violet staining, which do not discriminate between cells and matrix. A denser matrix, on the other hand, may contribute to the mechanisms making mixed biofilms more resistant than mono-species ones against external attack with enzymes, antimicrobials, or other agents (Simões et al., 2009; Burmølle et al., 2014; Sanchez-Vizuete et al., 2015). The shrinkage of the matrix could be possibly caused by the production of an additional extracellular matrix component as a result of the interaction between species, such as amyloid fibers. 
These surface-associated proteins, produced by some members of the Enterobacteriaceae family such as Escherichia coli and Salmonella, have also been described in certain $P$. fluorescens strains (Larsen et al., 2007; Dueholm et al., 2010; Zhou et al., 2012). In addition, other forms of alteration of the original P. fluorescens matrix framework may be involved (Steinberg and Kolodkin-Gal, 2015). According to Periasamy et al. (2015), polysaccharide composition of an individual species significantly impacts mixed species biofilm development and the emergent properties of such communities. If an abundant and extracellular matrix such as that produced by $P$. fluorescens can be considered as "public goods" when shared (Nadell et al., 2009), a reinforced, more compact matrix, induced if not produced, by L. monocytogenes in binary biofilms with Pseudomonas, could perhaps be considered as L. monocytogenes's contribution to enhanced public goods, providing more protection in spite of less growth, to both partners.

Biofilm aging appeared in this work to involve more changes than cell dispersal, such as structural modifications and cell regrowth. For one thing, not all cells seemed to get detached in these rather old biofilms, just part of them. CLSM images of the old biofilms formed at $20^{\circ} \mathrm{C}$ (Figure 3B) showed that dispersal had cleared out cells from the surface, but many viable cells remained underneath, about $10^{6} \mathrm{P}$. fluorescens CFU $\mathrm{cm}^{-2}$ and $10^{4}-10^{5} \mathrm{CFU} \mathrm{cm}{ }^{-2}$ of L. monocytogenes (Table 1). There is another aspect worth noting. Practically only the matrix was accessible in those old biofilms. This could at least partly explain the fact that aging adds resistance against stress in general (Lee et al., 2014; Serra and Hengge, 2014). On the other hand, it suggests that enzymatic or other matrixeroding procedures may be a prerequisite to have access to old biofilm dwelling cells. Another issue related to age is regrowth. Here, no discrimination between residual and fresh cells was made, so it is not possible to know how many of the viable cells in old biofilms are in fact starting a new proliferation cycle.

Biofilm development at $4^{\circ} \mathrm{C}$ was not merely slower than at $20^{\circ} \mathrm{C}$, but cold stress had an impact on biofilm structure. The structural contraction or shrinkage observed as a result of coculture, was intensified by low temperature and culture time. Besides, biofilms grown at $4^{\circ} \mathrm{C}$, particularly binary ones, were more irregular in structure, thickness and matrix distribution

\section{REFERENCES}

Alavi, H. E. D., and Hansen, L. T. (2013). Kinetics of biofilm formation and desiccation survival of Listeria monocytogenes in single and dual species biofilms with Pseudomonas fluorescens, Serratia proteamaculans or Shewanella baltica on food-grade stainless steel surfaces. Biofouling 29, 1253-1268. doi: 10.1080/08927014.2013.835805

Andreani, N. A., Martino, M. E., Fasolato, L., Carraro, L., Montemurro, F., Mioni, R., et al. (2015). Tracking the blue: a MLST approach to characterise the Pseudomonas fluorescens group. Food Microbiol. 45, 148-158. doi: 10.1016/j.fm.2014.11.011

Bonsaglia, E. C. R., Silva, N. C. C., Fernades Júnior, A., Araújo Júnior, J. P., Tsunemi, M. H., and Rall, V. L. M. (2014). Production of biofilm by Listeria monocytogenes in different materials and temperatures. Food Control 35, 386391. doi: 10.1016/j.foodcont.2013.07.023
(Figure 3 and Table 2). Both P. fluorescens and L. monocytogenes are known to express at low temperatures a wide range of different membrane components and enzymatic activities (Regeard et al., 2000; Hemery et al., 2007; Chan and Wiedmann, 2009; Durack et al., 2013); some of them could be involved in the development of the mentioned biofilm features.

\section{CONCLUSION}

When this dual-species consortium develop biofilms on a solid surface, apparently species interaction, cold stress and aging contribute to a more compact structure than the one built by P. fluorescens in single species biofilms at $20^{\circ} \mathrm{C}$. The actual change in the matrix framework and the mechanism to obtain it, deserves further work, as the pathogen's shelter is thus reinforced. The types of biofilms resulting from the interaction between P. fluorescens and L. monocytogenes, cold stress and aging could be used as targets for cleaning and disinfection procedures.

\section{AUTHOR CONTRIBUTIONS}

$\mathrm{CP}$ : conception of the work; analysis and interpretation of the data; drafting the work. BO: design of the work; interpretation of the data; drafting and revising the work; Agreement to be accountable for all aspects of the work in ensuring that questions related to the accuracy or integrity of any part of the work are appropriately investigated and resolved. CS: drafting the work and revising it critically; Agreement to be accountable for all aspects of the work in ensuring that questions related to the accuracy or integrity of any part of the work are appropriately investigated and resolved.

\section{ACKNOWLEDGMENTS}

The authors thank Dr. J. V. Martínez-Suárez for L. monocytogenes strain S1, the Cytometry and Fluorescence Microscopy Center of the Complutense University of Madrid and Laura Muñoz for their skillful assistance and the Spanish Ministry of Economy and Competition for funding project AGL2010-22212-C02-01.

Bridier, A., Sanchez-Vizuete, P., Guilbaud, M., Piard, J. C., Naitali, M., and Briandet, R. (2015). Biofilm-associated persistence of foodborne pathogens. Food Microbiol. 45, 167-178. doi: 10.1016/j.fm.2014. 04.015

Burmølle, M., Ren, D., Bjarnsholt, T., and Sørensen, S. J. (2014). Interactions in multispecies biofilms: do they actually matter? Trends Microbiol. 22, 84-91. doi: 10.1016/j.tim.2013.12.004

Burmølle, M., Webb, J. S., Rao, D., Hansen, L. H., Sørensen, S. J., and Kjelleberg, S. (2006). Enhanced biofilm formation and increased resistance to antimicrobial agents and bacterial invasion are caused by synergistic interactions in multispecies biofilms. Appl. Environ. Microbiol. 72, 3916-3923. doi: 10.1128/AEM.03022-05

Carpentier, B., and Cerf, O. (2011). Review - Persistence of Listeria monocytogenes in food industry equipment and premises. Int. J. Food Microbiol. 145, 1-8. doi: 10.1016/j.ijfoodmicro.2011.01.005 
Carpentier, B., and Chassaing, D. (2004). Interactions in biofilms between Listeria monocytogenes and resident microorganisms from food industry premises. Int. J. Food Microbiol. 97, 111-122. doi: 10.1016/j.ijfoodmicro.2004. 03.031

Chan, Y. C., and Wiedmann, M. (2009). Physiology and genetics of Listeria monocytogenes survival and growth at cold temperatures. Crit. Rev. Food Sci. Nutr. 49, 237-253. doi: 10.1080/10408390701856272

Costerton, J. W., Lewandowski, Z., Caldwell, D. E., Korber, D. R., and LappinScott, H. M. (1995). Microbial biofilms. Annu. Rev. Microbiol. 49, 711-745. doi: 10.1146/annurev.mi.49.100195.003431

Dueholm, M. S., Petersen, S. V., Sonderkaer, M., Larsen, P., Christiansen, G., Hein, K. L., et al. (2010). Functional amyloid in Pseudomonas. Mol. Microbiol. 77, 1009-1020. doi: 10.1111/j.1365-2958.2010.07269.x

Durack, J., Ross, T., and Bowman, J. P. (2013). Characterisation of the transcriptomes of genetically diverse Listeria monocytogenes exposed to hyperosmotic and low temperature conditions reveal global stress-adaptation mechanisms. PLoS ONE 8:e73603. doi: 10.1371/journal.pone.0073603

Elias, S., and Banin, E. (2012). Multi-species biofilms: living with friendly neighbors. FEMS Microbiol. Rev. 36, 990-1004. doi: 10.1111/j.1574-6976.2012.00325.x

Fox, E. M., Solomon, K., Moore, J. E., Wall, P. G., and Fanning, S. (2014). Phylogenetic profiles of in-house microflora in drains at a food production facility: comparison and biocontrol implications of listeria-positive and negative bacterial populations. Appl. Environ. Microbiol. 80, 3369-3374. doi: 10.1128/AEM.00468-14

Giaouris, E., Heir, E., Desvaux, M., Hébraud, M., Møretrø, T., Langsrud, S., et al. (2015). Intra- and inter-species interactions within biofilms of important foodborne bacterial pathogens. Front. Microbiol. 6:841. doi: 10.3389/fmicb.2015.00841

Giaouris, E., Heir, E., Hebraud, M., Chorianopoulos, N., Langsrud, S., Moretro, T., et al. (2014). Attachment and biofilm formation by foodborne bacteria in meat processing environments: causes, implications, role of bacterial interactions and control by alternative novel methods. Meat Sci. 97, 298-309. doi: 10.1016/j.meatsci.2013.05.023

Guilbaud, M., Piveteau, P., Desvaux, M., Brisse, S., and Briandet, R. (2015). Exploring the diversity of Listeria monocytogenes biofilm architecture by highthroughput Confocal Laser Scanning Microscopy and the predominance of the honeycomb-like morphotype. Appl. Environ. Microbiol. 81, 1813-1819. doi: 10.1128/AEM.03173-14

Hemery, G., Chevalier, S., Bellon-Fontaine, M. N., Haras, D., and Orange, N. (2007). Growth temperature and OprF porin affect cell surface physicochemical properties and adhesive capacities of Pseudomonas fluorescens MF37. J. Ind. Microbiol. Biotechnol. 34, 49-54. doi: 10.1007/s10295-006-0160-x

Hoben, H. J., and Somasegaran, P. (1982). Comparison of the pour, spread, and drop plate methods for enumeration of Rhizobium spp in inoculants made from pre-sterilized peat. Appl. Environ. Microbiol. 44, 1246-1247.

Jahid, I. K., and Ha, S.-D. (2014). The paradox of mixed-species biofilms in the context of food safety. Comprehensive Rev. Food Sci. Food Saf. 13, 990-1011. doi: 10.1111/1541-4337.12087

Larsen, P., Nielsen, J. L., Dueholm, M. S., Wetzel, R., Otzen, D., and Nielsen, P. H. (2007). Amyloid adhesins are abundant in natural biofilms. Environ. Microbiol. 9, 3077-3090. doi: 10.1111/j.1462-2920.2007.01418.x

Lee, K. W. K., Periasamy, S., Mukherjee, M., Xie, C., Kjelleberg, S., and Rice, S. A. (2014). Biofilm development and enhanced stress resistance of a model, mixed-species community biofilm. ISME J. 8, 894-907. doi: 10.1038/ismej. 2013.194

Mann, E. E., and Wozniak, D. J. (2012). Pseudomonas biofilm matrix composition and niche biology. FEMS Microbiol. Rev. 36, 893-916. doi: 10.1111/j.15746976.2011.00322.x

Mellefont, L. A., McMeekin, T. A., and Ross, T. (2008). Effect of relative inoculum concentration on Listeria monocytogenes growth in co-culture. Int. J. Food Microbiol. 21, 157-168. doi: 10.1016/j.ijfoodmicro.2007.10.010

Moons, P., Michiels, C. W., and Aertsen, A. (2009). Bacterial interactions in biofilms. Crit. Rev. Microbiol. 35, 157-168. doi: 10.1080/104084109028 09431

Moretro, T., and Langsrud, S. (2004). Listeria monocytogenes: biofilm formation and persistence in food-processing environments. Biofilms 1, 107-121. doi: $10.1017 /$ S1479050504001322
Nadell, C. D., Xavier, J. B., and Foster, K. R. (2009). The sociobiology of biofilms. FEMS Microbiol. Rev. 33, 206-224. doi: 10.1111/j.1574-6976.2008. 00150.x

Orgaz, B., Lobete, M. M., Puga, C. H., and SanJose, C. (2011). Effectiveness of chitosan against mature biofilms formed by food related bacteria. Int. J. Mol. Sci. 12, 817-828. doi: 10.3390/ijms12010817

Ortiz, S., Lopez, V., Villatoro, D., Lopez, P., Davila, J. C., and MartínezSuárez, J. V. (2010). A 3-year surveillance of the genetic diversity and persistence of Listeria monocytogenes in an Iberian pig slaughterhouse and processing plant. Foodborne Pathogens Dis. 7, 1177-1184. doi: 10.1089/fpd.20 10.0535

Periasamy, S., Nair, H. A. S., Lee, K. W. K., Ong, J., Goh, J. Q. J., Kjelleberg, S., et al. (2015). Pseudomonas aeruginosa PAO1 exopolysaccharides are important for mixed species biofilm community development and stress tolerance. Front. Microbiol. 6:851. doi: 10.3389/fmicb.2015.00851

Puga, C. H., SanJose, C., and Orgaz, B. (2014). "Spatial distribution of Listeria monocytogenes and Pseudomonas fluorescens in mixed biofilms," in Listeria monocytogenes, Food Sources, Prevalence and Management Strategies, ed. E. C. Hambrick (New York, NY: Nova Publishers), 115-132.

Regeard, C., Mérieau, A., and Guespin-Michel, J. F. (2000). A bioluminescence assay for screening thermoregulated genes in a psychrotrophic bacterium Pseudomonas fluorescens. J. Appl. Microbiol. 88, 183-189. doi: 10.1046/j.13652672.2000.00952.x

Rieu, A., Briandet, R., Habimana, O., Garmyn, D., Guzzo, J., and Piveteau, P. (2008). Listeria monocytogenes EGD-e biofilms: no mushrooms but a network of knitted chains. Appl. Environ. Microbiol. 74, 4491-4497. doi: 10.1128/AEM.00255-08

Røder, H. L., Raghupathi, P. K., Herschend, J., Brejnrod, A., Knøchel, S., Sørensen, S. J., et al. (2015). Interspecies interactions result in enhanced biofilm formation by co-cultures of bacteria isolated from a food processing environment. Food Microbiol. 51, 18-24. doi: 10.1016/j.fm.2015. 04.008

Rodríguez-López, P., Saa-Ibusquiza, P., Mosquera-Fernandez, M., and LopezCabo, M. (2015). Listeria monocytogenes-carrying consortia in food industry. Composition, subtyping and numerical characterisation of mono-species biofilm dynamics on stainless steel. Int. J. Food Microbiol. 206, 84-95. doi: 10.1016/j.ijfoodmicro.2015.05.003

Ryser, E. T., and Marth, E. H. (2007). Listeria, listeriosis, and food safety, 3rd Edn. Boca Raton, FL: CRC Press.

Sanchez-Vizuete, P., Orgaz, B., Aymerich, S., Le Coq, D., and Briandet, R. (2015). Pathogens protection against the action of disinfectants in multispecies biofilms. Front. Microbiol. 6:705. doi: 10.3389/fmicb.2015. 00705

Sasahara, K., and Zottola, E. (1993). Biofilm formation by Listeria monocytogenes utilizes a primary colonizing microorganism in flowing systems. J. Food Protection 56, 1022-1028.

Serra, D. O., and Hengge, R. (2014). Stress responses go three dimensional the spatial order of physiological differentiation in bacterial macrocolony biofilms. Environ. Microbiol. 16, 1455-1471. doi: 10.1111/1462-2920. 12483

Silby, M. W., Winstanley, C., Godfrey, S. A. C., Levy, S. B., and Jackson, R. W (2011). Pseudomonas genomes: diverse and adaptable. FEMS Microbiol. Rev. 35, 652-680. doi: 10.1111/j.1574-6976.2011.00269.x

Simões, M., Simões, L. C., and Vieira, M. J. (2009). Species association increases biofilm resistance to chemical and mechanical treatments. Water Res. 43, 229-237. doi: 10.1016/j.watres.2008.10.010

Srey, S., Jahid, I. K., and Ha, S. D. (2013). Biofilm formation in food industries: a food safety concern. Food Control 31, 572-585. doi: 10.1016/j.foodcont.2012.12.001

Steinberg, N., and Kolodkin-Gal, I. (2015). The matrix reloaded: how sensing the extracellular matrix synchronizes bacterial communities. J. Bacteriol. 197, 2092-2103.

Stewart, P. S., and Franklin, M. J. (2008). Physiological heterogeneity in biofilms. Nat. Rev. Microbiol. 6, 199-210. doi: 10.1038/nrmicro1838

Valderrama, W. B., and Cutter, C. N. (2013). An ecological perspective of Listeria monocytogenes biofilms in food processing facilities. Crit. Rev. Food Sci. Nutr. 53, 801-817. doi: 10.1080/10408398.2011.561378 
Warriner, K., and Namvar, A. (2009). What is the hysteria with Listeria? Trends Food Sci. Technol. 20, 245-254. doi: 10.1016/j.tifs.2009. 03.008

Yang, L. A., Liu, Y., Wu, H., Hoiby, N., Molin, S., and Song, Z. J. (2011). Current understanding of multi-species biofilms. Int. J. Oral Sci. 3, 74-81. doi: $10.4248 /$ IJOS11027

Zhou, Y., Smith, D., Leong, B. J., Brännström, K., Almqvist, F., and Chapman, M. R. (2012). Promiscuous cross-seeding between bacterial amyloids promotes interspecies biofilms. J. Biol.Chem. 287, 35092-35103. doi: 10.1074/jbc.M112.383737
Conflict of Interest Statement: The authors declare that the research was conducted in the absence of any commercial or financial relationships that could be construed as a potential conflict of interest.

Copyright $\odot 2016$ Puga, Orgaz and SanJose. This is an open-access article distributed under the terms of the Creative Commons Attribution License (CC BY). The use, distribution or reproduction in other forums is permitted, provided the original author(s) or licensor are credited and that the original publication in this journal is cited, in accordance with accepted academic practice. No use, distribution or reproduction is permitted which does not comply with these terms. 